\begin{tabular}{|c|l|}
\hline Title & Climatological mean features and interannual to decadal variability of ring formations in the Kuroshio Extension region \\
\hline Author(s) & Sasaki, Y oshi N.; Minobe, Shoshiro \\
\hline Citation & $\begin{array}{l}\text { Journal of oceanography, 71/5), 499-509 } \\
\text { https://doi.org/10.1007/310872-014-0270-4 }\end{array}$ \\
\hline Issue Date & $2015-10$ \\
\hline Doc URL & http://hdl.handle.net/2115/60459 \\
\hline Rights & The final publication is available at Springer via http://dx.doi.org/10.1007/s10872-014-0270-4 \\
\hline Type & article (author version) \\
\hline File Information & KErings.pdf \\
\hline
\end{tabular}

Instructions for use 


\title{
Climatological mean features and interannual to decadal variability of ring formations in the Kuroshio Extension region
}

\author{
Yoshi N. Sasaki and Shoshiro Minobe \\ Graduate School of Science, Hokkaido University, Sapporo, Japan
}

Keywords: Kuroshio Extension; pinch-off ring; jet; heat transport; interannual to decadal variability

Journal of Oceanography, 71, 499-509, doi:10.1007/s10872-014-0270-4

Corresponding author address: Yoshi N. Sasaki, Science 8th bldg, 8-3-20, Graduate School of Science, Hokkaido University, N10, W8, Sapporo, 060-0810, Japan.

E-mail: sasakiyo@mail.sci.hokudai.ac.jp

Tel: +81-11-706-4494

Fax: +81-11-706-4922 


\begin{abstract}
This study examines the climatological mean features of oceanic rings shed from the Kuroshio Extension (KE) jet and their interannual to decadal variability using satellite altimeter observations from October 1992 to December 2010. To objectively capture a ring shedding from the KE jet, a new method that consists of the detection of the jet length changes and the tracking of a ring is proposed. A spatial distribution of the ring formations in the $\mathrm{KE}$ region indicates that cyclonic (cold-core) rings were most frequently formed in the upstream region between $143^{\circ}-147^{\circ} \mathrm{E}$ around the steady meander of the KE jet. In contrast, most of anticyclonic (warm-core) rings formed in the downstream region west of the Shatsky Rise. These pinched-off rings in both the upstream and downstream regions generally propagated westward, but about two-third of the rings was reabsorbed by the jet. Nevertheless, about one-fourth of the meridional eddy heat transport at the latitude of the KE resulted from the rings that are not reabsorbed by the jet. The number of ring formations showed substantial interannual to decadal variability. In the upstream and downstream KE region, decadal and interannual variability was dominant, respectively. These fluctuations of the ring formations were negatively correlated with the strength of the KE jet. It is also revealed that the ring formation variations play an important role in sea surface temperature changes north of the KE jet.
\end{abstract}




\section{Introduction}

The Kuroshio Extension (KE), the western boundary current of the subtropical gyre in the North Pacific, flows eastward as a free jet after separating from the east coast of Japan at $35^{\circ} \mathrm{N}$ (Fig. 1). The KE region is one of the most energetic regions in the world ocean along with the Gulf Stream and the Antarctic Circumpolar Current regions (e.g., Wyrtki et al. 1976; Shum et al. 1990; Ducet et al. 2000). This strong eddy activity is accompanied by large transports of water properties, such as momentum, heat and nutrient (e.g., Stammer 1998; Qiu and Chen 2005a; Rainville et al. 2007; Sasai et al. 2010; Yim et al. 2010; Aoki et al. 2013). The strong eddy activity in the KE region is mainly owing to perturbations of the KE jet (i.e. meander) and eddies shed from the jet (Fig. 2), which are a common feature in western boundary current regions, such as the Gulf Stream and the Agulhas Current regions (e.g., Joyce et al. 1984; Kawamura et al. 1986; Auer 1987; Lutjeharms 1988; Olson 1991). Hereafter, we refer to an eddy shed from a jet as a ring. This ring formation in the KE region is the main focus of the present study.

A ring plays important roles in the eddy transport. A ring contains large amounts of anomalous heat and salinity, and transports them across the jet (e.g., Jochumsen et al. 2010; Souza et al. 2011). Also, a ring acts to remove energy from the jet and reduce a potential vorticity gradient associated with the jet (Olson 1991; Bush et al. 1995), while may reinforce the jet by momentum flux convergence (e.g., Waterman and Hoskins 2013). In addition, a ring is often accompanied by strong upwelling structure (e.g., Martin and Richards 2001; McGillicuddy et al. 2007), which is important in marine ecosystems by vertically transporting nutrients into the euphotic zone. In the KE region, the rings shed from the jet and their importance have been reported (e.g., Mizuno and White 1983; Kawamura et al. 1986; Oka et al. 2011). Yasuda et al. (1992) found from in-situ observations that a warm-core ring carried a large amount of North Pacific subtropical mode water. Qiu et al. (2007) revealed substantial influence of a cyclonic ring on property changes of North Pacific subtropical mode water from satellite altimeter and Argo data. Sugimoto and Hanawa (2011) pointed out that when many pinch-off rings are found in the upstream KE region, sea surface temperatures (SSTs) tend to be warm in the north of the upstream KE jet.

However, spatial and temporal distributions of ring formations and their behavior in the KE region have not been fully understood. The recent advances in 
satellite observations allow to more comprehensively examine eddy activities, but these previous studies did not distinguish among a pinched-off ring, a meander of a jet, and other mesoscale eddies (e.g., Chelton et al. 2007; Itoh and Yasuda 2010; Kouketsu et al. 2012). This is probably because it is difficult to distinguish among them, but there are significant differences. A strong eddy (e.g., ring) tends to trap water masses in its interior region, but this is not the case for a weak eddy (McWilliams and Flierl 1979; Chelton et al. 2011) and for a meander of a jet (Cushman-Roisin 1993). A propagation tendency and the corresponding upwelling structure are also different between a ring and a meander (Cushman-Roisin et al. 1990, 1993; Mariano et al. 1996; Martin and Richards 2001; McGillicuddy et al. 2007). Important questions remain unanswered: Where do most ring formations occur in the KE region? How frequently are the rings formed? How large is transports by the rings? One of the purposes of the present study is therefore to comprehensively examine the ring formations in the KE region and to answer these questions. To this end, we propose a new method for objectively capturing ring formation events.

Furthermore, how interannual to decadal fluctuations of the ring formations are related to a state of the KE jet remains unclear. It is well known that the KE jet undergoes prominent fluctuations on decadal timescales (e.g., Deser et al. 1999; Schneider et al. 2002; Taguchi et al. 2007; Sasaki and Schneider 2011; Sasaki et al. 2013). Qiu and Chen (2005b) showed that when the eddy activity in the KE region is high and low, the KE jet is weakening and strengthening, respectively, and referred to the former as a stable state and the latter as an unstable state. Nevertheless, a connection between interannual to decadal variability of the ring formations and the state of the KE jet has not been investigated, yet. Hence, we will investigate this relationship. Also, we will examine an influence of the ring formation variations on water-mass property changes around the KE region.

The rest of this paper is organized as follows. We describe datasets and a method for detecting a ring shedding from the KE jet in section 2. In sections 3 and 4, we examine climatological mean features and interannual to decadal variability of ring formations, respectively. Meridional eddy heat transport and its influence on surrounding ocean conditions are also investigated in these sections. Section 5 is a summary and discussion.

\section{Data and Methods}




\section{a. Datasets}

We use the reference version of daily sea surface height, and meridional and zonal surface geostrophic velocity data provided by Archiving, Validation and Interpretation of Satellite Oceanographic data (AVISO) from satellite altimetry combined observations from TOPEX/Poseidon, ERS-1/2, Jason-1 and Envisat from 14 October 1992 to 31 December 2010 on a $0.25^{\circ} \times 0.25^{\circ}$ (Ducet and Le Traon 2001). The mean sea surface height of this dataset was determined by applying the mean dynamic topography (Rio and Hernandez 2004). A SST dataset is on a $0.25^{\circ} \times 0.25^{\circ}$ grid of the version 2 of the Optimum Interpolation SST product (OISSTv2, Reynolds et al. 2007) provided by the National Oceanic and Atmospheric Administration (NOAA). This dataset uses in-situ and the Advanced Very High Resolution Radiometer (AVHRR) SST data.

\section{b. A method to detect a ring formation}

Our method to objectively detect a ring shedding event consists of three steps. As the first step, the path of the KE jet axis is determined at each day. In this study, we consider the KE jet as a single jet, following previous studies (e.g., Qiu and Chen 2005; Taguchi et al. 2007; Sasaki and Schneider 2011). Thus, we ignore the bifurcation branches of the KE jet (e.g., one branch around the Shatsky Rise shown in Mizuno and White 1983), and only focus on ring formation and absorption by the main part of the KE jet. The path of the jet is defied by a contour line of a fixed sea surface height, which accompanies strong absolute velocity. To determine the contour value of the jet axis, we identify a path of a fixed continuous contour of sea surface height from the east coast of Japan to $170^{\circ} \mathrm{E}$ in the range from 60 to $120 \mathrm{~cm}$ at $10-\mathrm{cm}$ intervals at each day (see Fig. 1), and averaged surface absolute velocity along each continuous contour. The results showed that the sea surface height contour that has a maximum absolute velocity exhibits substantial seasonal variability (blue line in Fig. 3). These sea surface height values are high in autumn (September-November) and low in spring (March-May), which is mainly due to seasonal large-scale steric height changes (e.g., Gill and Niller 1973). Thus, we calculated the seasonal cycle of these sea surface height values that is estimated by fitting to annual and semi-annual cycles using a least squares method (red line in Fig. 3), and a contour line that has these seasonally changed sea surface height values is employed to define the path of the KE jet axis at each day. 
After determining the path of the KE jet axis, as the second step, we calculate the length of the $\mathrm{KE}$ jet from $140^{\circ} \mathrm{E}$ to $170^{\circ} \mathrm{E}$ at each time step, and investigate its temporal fluctuation. If the length of the jet decreases by more than $300 \mathrm{~km}$ per day, we consider this decreasing as a candidate of a ring formation. In the case of Fig. 2, the length of the jet on 11 July 2010 is $5,018 \mathrm{~km}$, and decreases to 4,543 km on 12 July 2010. By these first and second procedures, we can distinguish a ring from a meander of the jet. We can also distinguish a pinched-off ring from a mesoscale recirculation, because the formation of a mesoscale recirculation does not induce the decrease of the jet length. Note that results are less sensitive to the choice of the threshold of the length change. Even if the threshold of the length change is modified for a range from $200 \mathrm{~km}$ to $400 \mathrm{~km}$, the differences in the number of the rings in the KE region and in the ratio of the rings reabsorbed by the jet are less than $10 \%$ (Fig. 4).

As the last step, when the decrease of the jet length occurs, we track the pinched-off rings using a neighbor enclosed area tracking (NEAT) method (Inatsu 2009; Inatsu and Amada 2013). In this method, a ring is defined as a closed area that meets some criterion, and is tracked by concatenating overlapped area of that ring in a neighboring time frame (i.e., daily). Thus, this method can continuously track rings even if they split (i.e., one ring splits into two) or merge (e.g. two rings merge to one), if rings after splitting or merging meet the criterion. Here, the pinched-off cyclonic (anticyclonic) ring is defined as a closed area whose sea surface height value is lower (higher) than the aforementioned value of the KE jet axis (Fig. 3) and that has positive (negative) surface relative vorticity. This excludes pinched-off weak rings. By this tracking, we can exclude short-lived rings that disappear or are reabsorbed by the KE jet using a 13-day lifetime threshold. If the ring survives more than 14 days, we consider that the ring formation event has occurred.

\section{Climatological mean features}

Table 1 summarizes a census of the rings shed from the KE jet from October 1992 to December 2010. During this period, we observed 218 ring formations. Thus, the frequency of the ring formations was about 11.9 events per year. The formation of anticyclonic rings (107 events) was comparable to that of cyclonic rings (111 events). Interestingly, 141 pinched-off rings (78 anticyclonic and 63 cyclonic rings) were reabsorbed by the KE jet (Table 1). This means that only one-third of the rings decayed apart from the KE jet. 
Figure 5 shows the spatial distribution of the ring formations in the KE region. The formations of the cyclonic (cold-core) and anticyclonic (warm-core) rings generally occurred south and north of the mean path of the KE jet, respectively. Upon a closer inspection, the cyclonic rings tended to be frequently shed in the upstream KE region, especially between $143^{\circ}-147^{\circ} \mathrm{E}$ around the steady meander of the jet (Fig. 5a). This is consistent with Nakano et al. (2013), who pointed out frequent formations of cold-core rings there. The anticyclonic rings were also formed in this region, but their formation number was about half of that of the cyclonic rings (Fig. 5b). The anticyclonic rings were most frequently shed in the downstream KE region west of the Shatsky Rise. About one-third of the anticyclonic ring formations were concentrated in this region. The cyclonic ring formations were also observed there. This result suggests that the Shatsky Rise plays an important role in ring formations. Consistently, past numerical studies suggested that the Shatsky Rise acts as an obstacle and induces a large meander of the KE jet (Chao 1994; Hurlburt and Metzger 1998; Nishihama and Ikeda 2013). Fujii et al. (2013) showed using an ocean general circulation model that the pinched-off

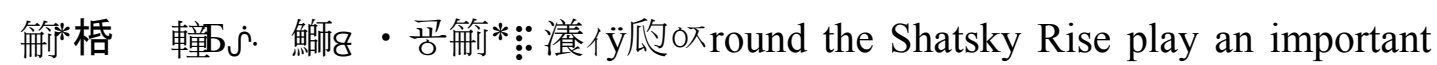
role in transportation of the North Pacific Intermediate Water.

Figure 6 shows the spatial distribution of the ring reabsorptions by the KE jet. The anticyclonic rings were frequently reabsorbed by the KE jet at west of the Shatsky Rise, i.e., the formation region of these rings. Similarly, the cyclonic rings tended to be reabsorbed by the jet in the upstream region. The location of the reabsorptions slightly shifts westward compared to the spatial distribution of the ring formations (Fig. 5). This is consistent with the westward movements of the rings as will be shown below. The rings that are not reabsorbed by the KE jet are expected to play more roles in transports of water properties. This point will be further discussed later.

The pinched-off rings generally propagated westward, while they also meridionally spread between $30^{\circ}-39^{\circ} \mathrm{N}$ (Fig. 7). The mean westward propagation speed of anticyclonic and cyclonic rings was $2.59 \mathrm{~cm} \mathrm{~s}^{-1}$ and $3.44 \mathrm{~cm} \mathrm{~s}^{-1}$, respectively. This zonal propagation speed is consistent with the theory (e.g., McWilliams and Flierl 1979; Cushman-Roisin et al. 1990) and previous observational results (e.g., Ebuchi and Hanawa 2001; Itoh and Yasuda 2010). There was no significant difference of the westward propagation speed between the upstream and downstream regions (not shown). The faster propagation of the cyclonic rings is probably due to the difference of the Rossby deformation radius. That is, a ring at low latitude propagates faster than that at 
high latitude, because the Rossby deformation radius is larger in lower latitude (Chelton et al. 1998). The meridional speed of anticyclonic (cyclonic) rings was $0.11 \mathrm{~cm} \mathrm{~s}^{-1}$ ($0.08 \mathrm{~cm} \mathrm{~s}^{-1}$ ) on average, which is much smaller than their aforementioned zonal speed and is not significantly different from zero.

It is interesting to compare the propagation tendency between these rings and a meander of the KE jet. The meander of the KE jet propagated eastward west of $145^{\circ} \mathrm{E}$, but propagated westward east of $145^{\circ} \mathrm{E}$ (Fig. 8). This implies that the advection effect is more important for the KE meander than the beta effect in the former region, while the opposite is the case in the latter region (thin-jet theory by Cushman-Roisin et al. 1993). This is reasonable because the KE jet is stronger in the upstream region than the downstream region. This eastward propagation of the meander in the upstream region was opposite to the westward propagation of the rings (Fig. 7). Even if we check the movement of the rings only east of $145^{\circ} \mathrm{E}$, the rings tended to move westward. These results confirm that the physical properties of the rings are different from those of the meander.

It is worth noting that the phase speed of the meander of the KE jet was nearly zero between $143^{\circ}-147^{\circ} \mathrm{E}$ (Fig. 8), where the cyclonic and anticyclonic rings were frequently formed (Fig. 5). Lee and Cornillon (1996) pointed out that a ring formation tends to occur where the phase speed of the meander is zero in the Gulf Stream region, because the advection effect is balanced to the beta effect so that the meander tends to be steady. Hence, our results in the KE region are consistent with the hypothesis by Lee and Cornillon (1996). The upstream KE region between $143^{\circ}-147^{\circ} \mathrm{E}$ is a favorable condition for the generation of rings.

Next, we examine the properties of the rings shed from the KE jet as a function of a longitude where the corresponding ring was shed from the KE jet (Fig. 9). Figure 9a shows the amplitude of a ring, which is defined as absolute values of sea level anomalies (SLAs) averaged over the ring. The mean value of the amplitude was about $0.40 \mathrm{~m}$ (see also Table 1), which was relatively large compared to typical mesoscale eddies in the world oceans (e.g., a few centimeter; Chelton et al. 2007; 2011). Obviously, the amplitude of the ring was negatively proportional to the longitude. The amplitude of the rings was up to $0.81 \mathrm{~m}$ in the upstream $\mathrm{KE}$ region, and decreases toward east. Because the KE jet is stronger in the upstream region than the downstream region, this result suggests that stronger jet yields in stronger rings. In addition, the 
amplitude of cyclonic rings in the upstream KE region tended to be larger than that of anticyclonic rings.

Consistently, the relative vorticity averaged over the ring was also negatively proportional to the longitude (Fig. 9b). The relative vorticity was about $1.0 \times 10^{-5} \mathrm{~s}^{-1}$ in the downstream KE region, and the relative vorticity reached about $4.0 \times 10^{-5} \mathrm{~s}^{-1}$ in the upstream region. Since the Coriolis parameter $f$ is $8.37 \times 10^{-5} \mathrm{~s}^{-1}$ at $35^{\circ} \mathrm{N}$, the ratio between the relative vorticity of the rings and the planetary vorticity, which is equivalent to the Rossby number, was up to 0.5. Hence, the rings, especially in the upstream KE region, have a significant nonlinear property. Again, the absolute value of relative vorticity of cyclonic rings tended to be larger than that of anticyclonic rings in the upstream region, where the cyclonic rings were frequently formed (Fig. 5). Similar difference of relative vorticity between the cyclonic and anticyclonic eddies around the upstream KE region has been reported by Itoh and Yasuda (2010).

On the contrary, the lifetimes and area of the rings did not depend on the formation longitude (Fig. 9c-d). The mean lifetime of the rings was about 2 months (Table 1). Almost all rings disappeared or were reabsorbed by the KE jet within a year, while one anticyclonic ring detached from the downstream KE region survived about 400 days. The mean size of the rings was $3.0 \times 10^{4} \mathrm{~km}^{2}$ (Table 1), which roughly corresponds to the diameter of $195 \mathrm{~km}$. The area of rings was independent of the amplitude of the rings. Since the amplitude of the rings in the upstream region was larger than that of the downstream region, the former rings have more water volume compared to the latter rings.

Before closing this section, we estimate a contribution of water masses trapped by the rings to across-jet heat transports to take advantage of our ring detecting method. This component is a portion of meridional eddy heat transport estimated by previous studies (e.g., Qiu and Chen 2005a; Itoh and Yasuda 2010), but has not been explicitly clarified yet. An anomalous across-jet heat flux by rings shed from the KE jet from 1993 to 2010 is calculated as follows. According to Chambers et al. (1997), a heat content anomaly $H$ associated with a ring is estimated as

$$
H=\rho c_{p} \eta / \alpha
$$

where $\rho=1,000 \mathrm{~kg} \mathrm{~m}^{-3}$ is the density, $c_{p}=4,000 \mathrm{~J} \mathrm{~kg}^{-1} \mathrm{~K}^{-1}$ is the specific heat for water, $\eta$ is SLA, and $\alpha=2 \times 10^{-4} \mathrm{~K}^{-1}$ is thermal expansion coefficient. These parameter values are the same as those in Itoh and Yasuda (2010). We ignore the salinity effect on density. If the rings that are reabsorbed by the KE jet are excluded (see Table 1), the 
frequency of pinched-off anticyclonic and cyclonic rings was 1.6 per year and 2.7 per year, respectively. The corresponding mean SLAs and areas of anticyclonic (cyclonic) rings were $+0.36 \mathrm{~m}(-0.46 \mathrm{~m})$ and $2.4 \times 10^{4} \mathrm{~km}^{2}\left(2.0 \times 10^{4} \mathrm{~km}^{2}\right)$, respectively. By the use of these values, the across-jet heat transports by anticyclonic rings were about $8.5 \times$ $10^{12} \mathrm{~W}$, and those by cyclonic rings were about $-1.5 \times 10^{13} \mathrm{~W}$. Thus, the total across-jet heat transport by the water mass trapped by the rings was $2.3 \times 10^{13} \mathrm{~W}(=0.023 \mathrm{PW})$. Using this value and the deviations of the heat transport by each ring, we estimated the 95\% confidence interval for this mean value based on the Student's t-test (Emery and Thomson 2004) as $1.9 \times 10^{13} \mathrm{~W}$ to $2.8 \times 10^{13} \mathrm{~W}$. Itoh and Yasuda (2010) reported comparable meridional eddy heat transport in the KE region $(0.02-0.03 \mathrm{PW})$. This result suggests that the rings play a dominant role in meridional eddy heat transport in the KE region. Note that because the amplitude of the rings decays and loses their heat anomalies even if the rings are reabsorbed by the jet, our estimation of the across-jet heat flux may be underestimated.

Our estimate is about one-fourth of the meridional eddy heat transport integrated across the North Pacific at the KE jet latitude reported by previous observational studies (e.g., about $1.0 \times 10^{14} \mathrm{~W}$ at $35^{\circ} \mathrm{N}$; see Fig. 14 in Qiu and Chen 2005a for an observational estimation and Fig. 2 in Aoki et al. 2013 for a numerical simulation). The remaining meridional eddy heat transport across the North Pacific at the KE jet latitude can be induced by the phase misalignment between temperature and velocity anomalies of the eddies (e.g., Qiu and Chen 2005a) around the KE region and the eddies east of the KE region. Hence, these results indicate that the water masses trapped by the rings substantially contribute to the meridional eddy heat transport in the North Pacific. The influence of the rings on the across-jet heat transports on interannual to decadal timescales will be discussed in the next section.

\section{Interannual to decadal variability}

In this section, we examine interannual to decadal fluctuations of the ring formations in the KE region, and their relationship to surrounding ocean conditions. Figure 10a shows yearly numbers of the ring formations in all KE regions from 1993 to 2010. The annual mean and the standard deviation of the ring formations were about 12.1 and 3.2, respectively. Both anticyclonic and cyclonic rings contributed to this 
interannual variability. In 1997, twenty rings (ten anticyclonic and ten cyclonic rings) shed from the KE jet, but only seven events were observed in 2006.

Although the interannual to decadal variability of the number of the ring formations in all $\mathrm{KE}$ regions was rather moderate, if we separate the $\mathrm{KE}$ region into the upstream and the downstream regions, the fluctuations becomes more drastic. In contrast to the case of all KE regions (Fig. 10a), decadal variability of the ring formation events was more prominent than their interannual variability in the upstream region (Fig. 10b). The formation of the rings has not been observed in 2002 and 2003. Furthermore, in the following two years, only one ring shedding event occurred in each year. On the contrary, ten rings shed from the jet in 1997 and 2001.

On the other hand, yearly numbers of the ring formation in the downstream region indicate more interannual variability rather than decadal variability (Fig. 10c). The correlation coefficient of the yearly numbers between the upstream and downstream region was -0.23 , which is not statistically significant at $95 \%$ confidence level. Here, the statistical significance is estimated by a Monte-Carlo test using 1000 random time series that are made by a phase randomization method (Kaplan and Glass 1995), in which surrogate time series are produced using observed spectrum and randomized phases so that timescales of the original time series are preserved in the surrogate time series. Note that the correlation of the total ring formation number with the anticyclonic (cyclonic) ring formation number was $0.84(0.32)$. This result means that the anticyclonic ring formations represented the total ring formations in the downstream KE region. This relation was not seen in the upstream region.

To investigate the relation of these interannual to decadal fluctuations of the ring formations in both the upstream and downstream regions to the state of the KE jet, we examine the relation of the ring formations to the strength of the KE jet. To this end, the strength changes of the KE jet is decomposed by an empirical orthogonal function (EOF) analysis for the annual mean surface absolute geostrophic velocity along the jet axis from $140^{\circ}-170^{\circ} \mathrm{E}$ in order to consider a spatial structure of the velocity changes. Spatial patterns and temporal coefficients of the leading two EOF modes are shown in Fig. 11. The result of the correlation analysis shows that the time series of the first EOF mode were negatively correlated with the number of the ring formations in the upstream $\mathrm{KE}$ region (Figs. $10 \mathrm{~b}$ and $11 \mathrm{~b}$ ). The correlation coefficient was -0.67 , which is statistically significant at $95 \%$ confidence level. Note that we also checked the relation 
between the ring formations in the upstream region and the latitude of the KE jet in the same way, but the relation was not statistically significant (not shown).

This relation of the ring formation variability in the upstream KE region with the strength changes of the KE jet suggests the connection between the ring formation events and the stable/unstable mode of the KE jet (Qiu and Chen 2005b; 2010). Qiu and Chen (2010) argued that the KE jet is the stable state from late 1992 to mid-1995 and from early 2002 to late 2005 , and the unstable state from mid-1995 to late 2001 and from early 2006 to late 2008 (end of their satellite data). Indeed, their stable state likely corresponds to the period when the formation of the rings in the upstream region was less frequent and vice versa (Fig. 10b). Thus, the decadal variability of the ring formations in the upstream KE region was likely related to the stable state and the unstable stated of the KE jet.

We also examine the relation of the ring formations in the downstream KE region to the strength of the KE jet. Interestingly, the number of ring formations in the downstream region was significantly correlated with the time series of the second EOF mode of the strength of the KE jet (Fig. 11c), which represents out-of-phase variability of the KE strength between the upstream and downstream regions (Fig. 11a). The correlation coefficient reached -0.57 (statistically significant at $95 \%$ confidence level). Thus, when the downstream jet was weak and the upstream jet was strong, the ring formations in the downstream region were more frequent. This relation was similar with the aforementioned relation of the ring formations in the upstream region. The ring formations in the downstream $\mathrm{KE}$ region also did not have a relation with the latitude of the KE jet (not shown).

Finally, we examine a relation of interannual to decadal fluctuations of the ring formations to SST changes around the KE region. Figure 12a shows the differences of SST between the periods when the number of the ring formations in the upstream KE region is high and low. The positive SST anomalies of about $2.5^{\circ} \mathrm{C}$ were found in the north of the upstream KE axis, consistent with the increasing of meridional eddy heat transport by the rings, although the negative SST anomalies were not found in the south of the KE jet axis. This is probably because warm water of anticyclonic rings is lighter than the water north of the KE jet, but cold water of cyclonic rings are heavier than the water south of the jet so that the anticyclonic rings more effectively influence SSTs. The positive SST anomalies north of the KE jet are consistent with the results by Sugimoto 
and Hanawa (2011), who showed that high eddy activity in the upstream KE region is associated with warm SSTs in the north of the upstream KE region.

Similar result is obtained in the case of the downstream KE region (Fig. 12b). The amplitude of positive SST anomalies in the north of the downstream KE axis was about $1.0^{\circ} \mathrm{C}$. The difference of the amplitude of SST anomalies between the upstream and downstream cases is probably due to the difference of the heat content anomalies of the rings (see Fig. 9a). Therefore, the across-jet heat flux by the pinched-off rings plays an important role in SST change around the KE region on interannual to decadal timescales.

\section{Summary and discussion}

We examined the climatological mean features of ring formations in the $\mathrm{KE}$ region and their interannual to decadal variability using satellite altimeter observations from October 1992 to December 2010. To objectively detect a formation of the ring shed from the KE jet, we proposed the new method that consists of the detection of the jet length changes and the tracking of ring movements. We observed 107 anticyclonic and 111 cyclonic ring formations in the all KE region, while about two-third of the rings returned to the KE jet (Fig. 6). A spatial distribution of the ring formations in the $\mathrm{KE}$ region indicated that cyclonic rings were most frequently formed in the upstream KE region between $143^{\circ}-147^{\circ} \mathrm{E}$ (Fig. 5a), where the phase speed of the KE meander changes its sign (Fig. 8). On the other hand, anticyclonic ring shedding events were most frequently observed west of the Shatsky Rise (Figs. 1 and 5b), suggesting an importance of the bottom topography for the ring formations. Both the cyclonic and anticyclonic rings generally propagated westward (Fig. 7), which is in contrast to eastward propagation of the meander of the upstream KE jet (Fig. 8). The amplitude and relative vorticity of the rings were negatively proportional to the longitude (Fig. 9a-b). In contrast, the lifetimes and area (radius) of the rings did not show such a tendency (Fig. 9c-d). It is also revealed that about one-fourth of the meridional eddy heat transport at the latitude of the KE was caused by the rings shed from the KE jet. To our knowledge, this is the first study to quantitatively estimate the climatological across-jet eddy heat flux by rings in the KE region.

The total number of the ring formations showed substantial variability on interannual to decadal timescales (Fig. 10). In the upstream region, the decadal variability was dominant (Fig. 10b), which is likely related to the stable and unstable 
states of the KE jet (Qiu and Chen 2005b; 2010). On the other hand, interannual variability was dominant in the downstream KE region (Fig. 10c). The decadal fluctuations of the ring formations in the upstream KE region were negatively correlated with the strength of the upstream KE jet (Fig. 11b). Similarly, the interannual variability of the ring formations in the downstream region was also related to the strength change of the jet (Fig. 11c). The increasing (decreasing) of the ring formations of both the upstream and downstream regions was associated with the warming (cooling) of SST north of the KE jet axis (Fig. 12). This result suggests that the variability of the ring formations significantly contributes to local heat balance on interannual to decadal timescales. SST variations around the KE region can influence the atmosphere over the North Pacific (e.g., Bond and Cronin 2008; Tokinaga et al. 2009; O'Reilly and Czaja 2014).

Our study shows that the formation of the rings is negatively correlated with the surface velocity of the KE jet on interannual and decadal timescales (Figs. 10 and 11). The simultaneous correlation analysis does not tell us the causality, but one possible explanation for this negative correlation is that the across-jet eddy heat transport by rings can induce or reinforce the weakening of the KE jet. Bush et al. (1995) showed from numerical experiments that the pinched-off rings act to reduce the potential vorticity gradient across the jet. Our speculation can partly explain the mechanism for the stable and unstable mode of the KE jet. Hence, it is desirable to investigate this issue using a numerical ocean model in the future.

The method employed in the present study for detecting the ring formation events may be improved in future studies. As mentioned in section 2, the KE jet has been assumed as a single jet and the main braches of bifurcated currents are only considered. Consequently, the present method does not count ring formations from other branches than the main KE jet, and thus those rings are not tracked. This may underestimate the number of the ring formation. Furthermore, we also missed the ring absorption by other bifurcation branches. However, this is likely rare, because the locations of the disappearance of the rings are not concentrated around other bifurcation branches (not shown). Another possible problem is the use of the jet length change to detect the ring formation event. This is assumed that the formation and absorption of rings do not occur at the same time. Although this happens rarely, this assumption also may underestimate ring formation events. We leave additional improvements of the method to a future study. 


\section{Acknowledgments}

We thank two anonymous reviewers for comments that helped to improve the manuscript. This research was supported by the Grant-in-Aid for Scientific Research on Innovative Areas Grant Number 22106008 and for Young Scientists (B) Grant Number 25800258, which are all funded by the Ministry of Education, Culture, Sports, Science, and Technology of Japan.

\section{References}

Aoki K, Minobe S, Tanimoto Y, and Sasai Y (2013) Southward eddy heat transport occurring along southern flanks of the Kuroshio Extension and the Gulf Stream in a $1 / 10^{\circ}$ global ocean general circulation model. J Phys Oceanogr 43:1899-1910.

Auer SJ (1987) Five-Year Climatological Survey of the Gulf Stream System and Its Associated Rings. J Geophys Res-Oceans 92:11709-11726.

Bond NA, and Cronin MF (2008) Regional Weather Patterns During Anomalous AirSea Fluxes at the Kuroshio Extension Observatory (Keo). J Clim 21:1680-1697.

Bush ABG, McWilliams JC, and Peltier WR (1995) The Formation of Oceanic Eddies in Symmetric and Asymmetric Jets. Part I: Early Time Evolution and Bulk Eddy Transports. J Phys Oceanogr 25:1959-1979.

Chambers DP, Tapley BD, and Stewart RH (1997) Long-period ocean heat storage rates and basin-scale heat fluxes from Topex. J Geophys Res-Oceans 102:10525-10533.

Chao SY (1994) Zonal Jets over Topography on a Beta-Plane, with Applications to the Kuroshio Extension over the Shatsky Rise. J Phys Oceanogr 24:1512-1531.

Chelton DB, Schlax MG, and Samelson RM (2011) Global Observations of Nonlinear Mesoscale Eddies. Prog Oceanogr 91:167-216.

Chelton DB, Schlax MG, Samelson RM, and de Szoeke RA (2007) Global Observations of Large Oceanic Eddies. Geophys Res Lett 34. doi: 10.1029/2007g1030812.

Cushman-Roisin B (1993) Trajectories in Gulf Stream Meanders. J Geophys ResOceans 98:2543-2554. doi: 10.1029/92JC02059.

Cushman-Roisin B, Tang B, and Chassignet EP (1990) Westward Motion of Mesoscale Eddies. J Phys Oceanogr 20:758-768.

Cushman-Roisin B, Pratt L, and Ralph E (1993) A General Theory for Equivalent Barotropic Thin Jets. J Phys Oceanogr 23:91-103. 
Deser C, Alexander MA, and Timlin MS (1999) Evidence for a Wind-Driven Intensification of the Kuroshio Current Extension from the 1970s to the 1980s. J Clim 12:1697-1706.

Ducet N, and Le Traon PY (2001) A comparison of surface eddy kinetic energy and Reynolds stresses in the Gulf Stream and the Kuroshio current systems from merged Topex/Poseidon and Ers-1/2 altimetric data. J Geophys Res 106:1660316622.

Ducet N, Le Traon PY, and Reverdin G (2000) Global High-Resolution Mapping of Ocean Circulation from Topex/Poseidon and Ers-1 and -2. J Geophys Res-Oceans 105:19477-19498. doi: 10.1029/2000JC900063.

Ebuchi N, and Hanawa K (2001) Trajectory of Mesoscale Eddies in the Kuroshio Recirculation Region. J Oceanogr 57:471-480.

Emery WJ, and Thomson RE (2004) Data Analysis Methods in Physical Oceanography. Second and Revised Edition, Elsevier, 638pp.

Fujii Y, Nakano T, Usui N, Matsumoto S, Tsujino H, and Kamachi M (2013) Pathways of the North Pacific Intermediate Water identified through the tangent linear and adjoint models of an ocean general circulation model, J Geophys Res 118: 20352051, doi:10.1002/jgrc.20094.

Gill AE, and Niller PP (1973) The Theory of the Seasonal Variability in the Ocean. Deep-Sea Res 20:141-177.

Hurlburt HE, and Metzger EJ (1998) Bifurcation of the Kuroshio Extension at the Shatsky Rise. J Geophys Res 103:7549-7566.

Inatsu M (2009) The Neighbor Enclosed Area Tracking Algorithm for Extratropical Wintertime Cyclones. Atmospheric Science Letters 10:267-272.

Inatsu M, and Amada S (2013) Dynamics and Geometry of Extratropical Cyclones in the Upper Troposphere by a Neighbor Enclosed Area Tracking Algorithm. J Clim 26:8641-8653.

Itoh S, and Yasuda I (2010) Characteristics of Mesoscale Eddies in the KuroshioOyashio Extension Region Detected from the Distribution of the Sea Surface Height Anomaly. J Phys Oceanogr 40:1018-1034.

Jochumsen K, Rhein M, Hüttl-Kabus S, and Böning CW (2010) On the propagation and decay of North Brazil Current rings. J Geophys Res 115: C10004. doi:10.1029/2009JC006042. 
Joyce T, and Coauthors (1984) Rapid Evolution of a Gulf Stream Warm-Core Ring. Nature 308:837-840.

Kaplan D, and Glass L (1995) Understanding Nonlinear Dynamics. Springer-Verlag, pp. 420.

Kawamura H, Mizuno K, and Toba Y (1986) Formation Process of a Warm-Core Ring in the Kuroshio-Oyashio Frontal Zone-December 1981-October 1982. Deep-Sea Res 33:1617-1640.

Kouketsu S, Tomita H, Oka E, Hosoda S, Kobayashi T, and Sato K (2012) The Role of Meso-Scale Eddies in Mixed Layer Deepening and Mode Water Formation in the Western North Pacific. J Oceanogr 68:63-77.

Lee T, and Cornillon P (1996) Propagation and Growth of Gulf Stream Meanders between 75 Degrees and 45 Degrees W. J Phys Oceanogr 26:225-241.

Lutjeharms JRE (1988) Meridional Heat Transport across the Sub-Tropical Convergence by a Warm Eddy. Nature 331:251-254.

Mariano AJ, Hitchcock GL, Ashjian CJ, Olson DB, Rossby T, Ryan E, and Smith SL (1996) Principal Component Analysis of Biological and Physical Variability in a Gulf Stream Meander Crest. Deep-Sea Res 43:1531-1565.

Martin AP, and Richards KJ (2001) Mechanisms for Vertical Nutrient Transport within a North Atlantic Mesoscale Eddy. Deep-Sea Res 48:757-773.

McGillicuddy DJ, and Coauthors (2007) Eddy/Wind Interactions Stimulate Extraordinary Mid-Ocean Plankton Blooms. Science 316:1021-1026.

McWilliams JC, and Flierl GR (1979) On the Evolution of Isolated, Nonlinear Vortices. J Phys Oceanogr 9:1155-1182.

Mizuno K, and White WB (1983) Annual and Interannual Variability in the Kuroshio Current System. J Phys Oceanogr 13:1847-1867.

Nakano H, Tsujino H, and Sakamoto K (2013) Tracer Transport in Cold-Core Rings Pinched Off from the Kuroshio Extension in an Eddy-Resolving Ocean General Circulation Model. J Geophys Res-Oceans 118:5461-5488.

Nishihama Y, and Ikeda M (2013) Instability Processes of Mesoscale Features in the Kuroshio Extension Reproduced through Assimilation of Altimeter Data into a Quasi-Geostrophic Model Using the Variational Method. J Oceanogr 69:135-146.

O'Reilly CH, and Czaja A (2014) The Response of the Pacific Storm Track and Atmospheric Circulation to Kuroshio Extension Variability. Quarterly Journal of the Royal Meteorological Society: DOI:10.1002/qj.2334. 
Oka E, Suga T, Sukigara C, Toyama K, Shimada K, and Yoshida J (2011) "Eddy Resolving" Observation of the North Pacific Subtropical Mode Water. J Phys Oceanogr 41:666-681.

Olson DB (1991) Rings in the Ocean. Annual Review of Earth and Planetary Sciences 19:283-311.

Qiu B, and Chen S (2005a) Eddy-induced heat transport in the subtropical North Pacific from Argo, TMI, and altimetry measurements. J Phys Oceanogr 35:458-473.

Qiu B, and Chen S (2005b) Variability of the Kuroshio Extension jet, recirculation gyre, and mesoscale eddies on decadal time scales. J Phys Oceanogr 35:2090-2103.

Qiu B, and Chen S (2010) Eddy-Mean Flow Interaction in the Decadally Modulation Kuroshio Extension System. Deep-Sea Res 57:1098-1110.

Qiu B, Chen S, and Hacker P (2007) Effect of Mesoscale Eddies on Subtropical Mode Water Variability from the Kuroshio Extension System Study (KESS). J Phys Oceanogr 37:982-1000.

Rainville L, Jayne SR, McClean JL, and Maltrud ME (2007) Formation of Subtropical Mode Water in a High-Resolution Ocean Simulation of the Kuroshio Extension Region. Ocean Modelling 17:338-356.

Reynolds RW, Smith TM, Liu C, Chelton DB, Casey KS, and Schlax MG (2007) Daily high-resolution-blended analyses for sea surface temperature. J Clim 20:5473-5496.

Rio M-H, and Hernandez F (2004) A Mean Dynamic Topography Computed over the World Ocean from Altimetry, in Situ Measurements, and a Geoid Model. J Geophys Res 109:C12032. doi: 10.1029/2003JC002226.

Sasai Y, Richards KJ, Ishida A, and Sasaki H (2010) Effects of Cyclonic Mesoscale Eddies on the Marine Ecosystem in the Kuroshio Extension Region Using an EddyResolving Coupled Physical-Biological Model. Ocean Dynamics 60:693-704.

Sasaki YN, and Schneider N (2011) Decadal Shifts of the Kuroshio Extension Jet: Application of Thin-Jet Theory. J Phys Oceanogr 41:979-993.

Sasaki YN, Minobe S, and Schneider N (2013) Decadal Response of the Kuroshio Extension Jet to Rossby Waves: Observation and Thin-Jet Theory. J Phys Oceanogr 43:442-456.

Schneider N, Miller AJ, and Pierce DW (2002) Anatomy of North Pacific Decadal Variability. J Clim 15:586-605. 
Shum CK, Werner RA, Sandwell DT, Zhang BH, Nerem RS, and Tapley BD (1990) Variations of Global Mesoscale Eddy Energy Observed from Geosat. J Geophys Res-Oceans 95:17865-17876.

Souza J MAC, de Boyer Montégut C, Cabanes C and Klein P (2011) Estimation of the Agulhas ring impacts on meridional heat fluxes and transport using ARGO floats and satellite data. Geophys Res Lett 38: L21602 doi:10.1029/2011GL049359.

Stammer D (1998) On Eddy Characteristics, Eddy Transports, and Mean Flow Properties. J Phys Oceanogr 28:727-739.

Sugimoto S, and Hanawa K (2011) Roles of Sst Anomalies on the Wintertime Turbulent Heat Fluxes in the Kuroshio-Oyashio Confluence Region: Influences of Warm Eddies Detached from the Kuroshio Extension. J Clim 24:6551-6561.

Taguchi B, Xie S-P, Schneider N, Nonaka M, Sasaki H, and Sasai Y (2007) Decadal Variability of the Kuroshio Extension: Observations and an Eddy-Resolving Model Hindcast. J Clim 20:2357-2377.

Tokinaga H, Tanimoto Y, Xie S-P, Sampe T, Tomita H, and Ichikawa H (2009) Ocean Frontal Effects on the Vertical Development of Clouds over the Western North Pacific: In Situ and Satellite Observations. J Clim 22:4241-4260.

Waterman S, and Hoskins BJ (2013) Eddy Shape, Orientation, Propagation, and Mean Flow Feedback in Western Boundary Current Jets. J Phys Oceanogr 43:1666-1690. White WB, Meyers GA, Donguy JR, and Pazan SE (1985) Short-Term Climatic Variability in the Thermal Structure of the Pacific Ocean During 1979-82. J Phys Oceanogr 15:917-935.

Wyrtki K, Magaard L, and Hager J (1976) Eddy Energy in the Oceans. J Geophys Res 81:2641-2646.

Yasuda I, Okuda K, and Hirai M (1992) Evolution of a Kuroshio Warm-Core RingVariability of the Hydrographic Structure. Deep-Sea Res 39, 131-161.

Yim BY, Noh Y, Qiu B, You SH, and Yoon JH (2010) The vertical structure of eddy heat transport simulated by an eddy-resolving OGCM. J Phys Oceanogr 40:340-353. 
Table 1. Statistics of the rings shed from the KE jet from October 1992 to December 2010.

\begin{tabular}{|c|c|c|c|c|c|c|}
\hline & \multicolumn{2}{|c|}{ Number } & \multirow{2}{*}{$\begin{array}{l}\text { Amplitude } \\
\text { (m) }\end{array}$} & \multirow{2}{*}{$\begin{array}{c}|\zeta| \\
\left(\times 10^{-5} \mathrm{~s}^{-1}\right)\end{array}$} & \multirow{2}{*}{$\begin{array}{c}\text { Lifetimes } \\
\text { (days) }\end{array}$} & \multirow{2}{*}{$\begin{array}{c}\text { Area } \\
\left(\times 10^{4} \mathrm{~km}^{2}\right)\end{array}$} \\
\hline & all & reabsorb & & & & \\
\hline All & 218 & 141 & 0.40 & 1.7 & 56.5 & 3.0 \\
\hline Anticyclonic & 107 & 78 & 0.36 & 1.4 & 56.4 & 3.2 \\
\hline Cyclonic & 111 & 63 & 0.44 & 2.0 & 56.6 & 2.8 \\
\hline
\end{tabular}

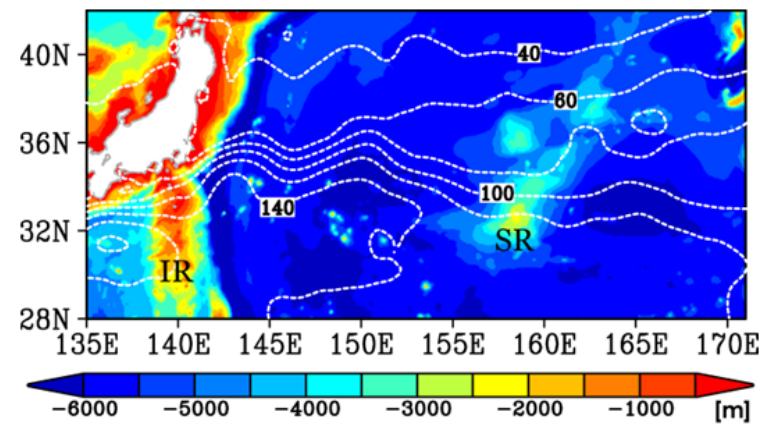

Figure 1. Mean sea surface height (contour) and geography (color) derived from ETOPO5 provided by from the National Geophysical Data Center. The contour interval is $20 \mathrm{~cm}$. IR and SR denote the Izu Ridge and the Shatsky Rise, respectively. 

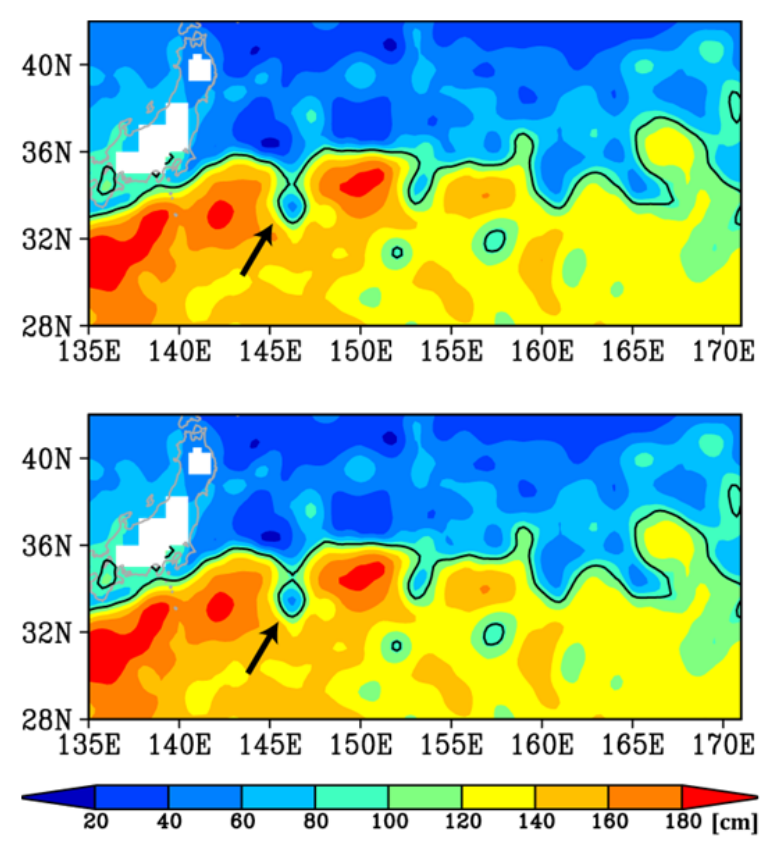

Figure 2. An example of a cyclonic ring shed from the Kuroshio Extension (KE) jet from 11 July 2010 (upper panel) to 12 July 2010 (lower panel). Color indicates sea surface height, and black contour indicates the path of the KE jet axis and the pinched-off ring.

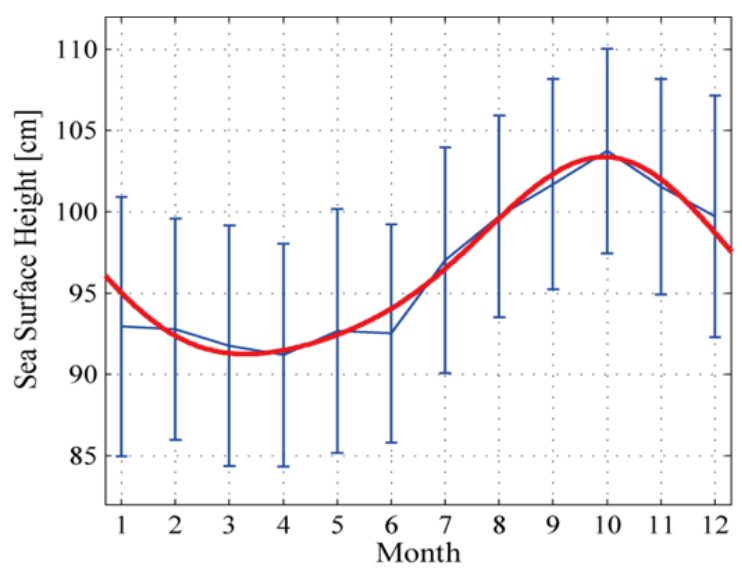

Figure 3. Mean values and their standard deviations of the sea surface height contour that has a maximum absolute velocity as a function of month (blue line and error bar). The standard deviations are calculated from the daily data. The red line denotes the seasonal cycle that is estimated by fitting to annual and semi-annual cycles using a least squares method. 


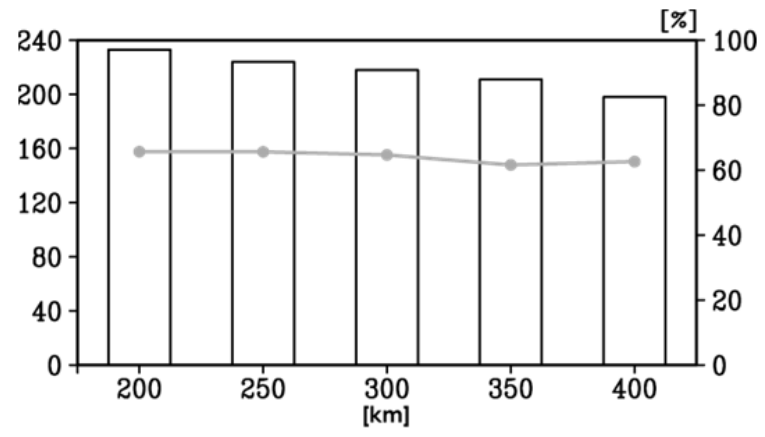

Figure 4. The number of ring formations in the KE region from October 1992 to December 2010 (black bar, left axis) and the ratio of the rings reabsorbed by the KE jet (gray line, right axis) as a function of the threshold of the length change to detect the ring formation.
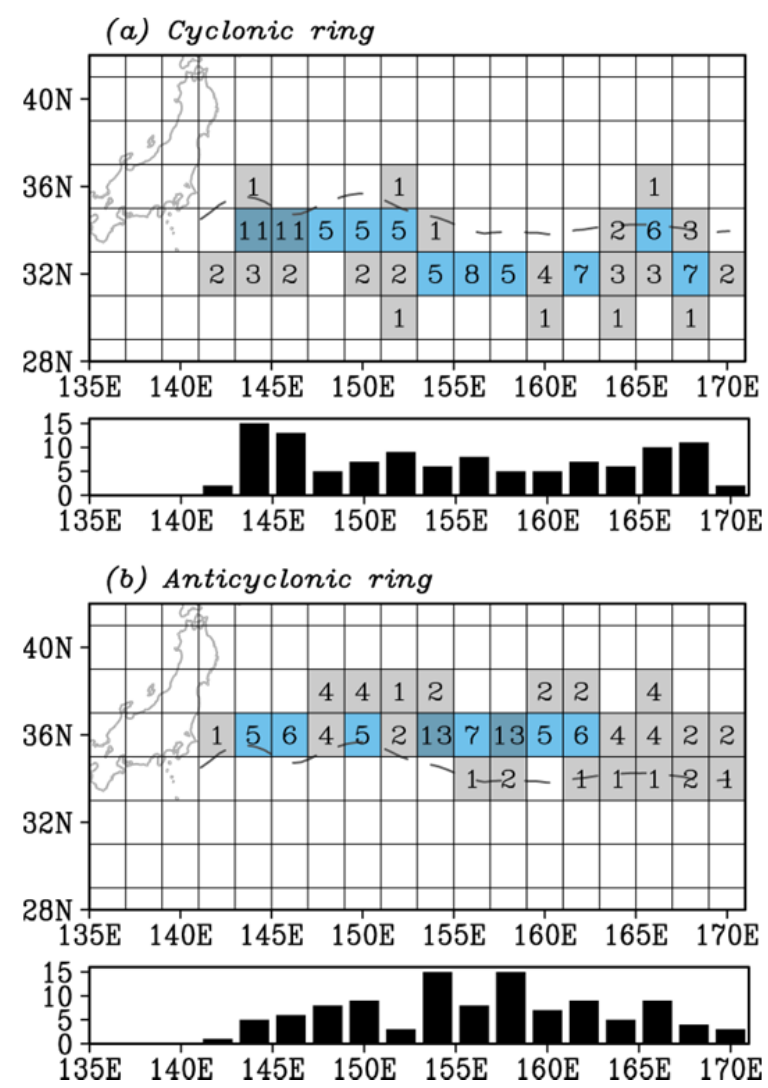

Figure 5. A spatial distribution of the number of (a) cyclonic and (b) anticyclonic ring formations in the KE region from October 1992 to December 2010 averaged in a $2^{\circ}$ latitude by $2^{\circ}$ longitude box. Dashed curve indicates the climatological path of the KE jet. The meridional integration of the number of rings is shown at the bottom of each panel. 

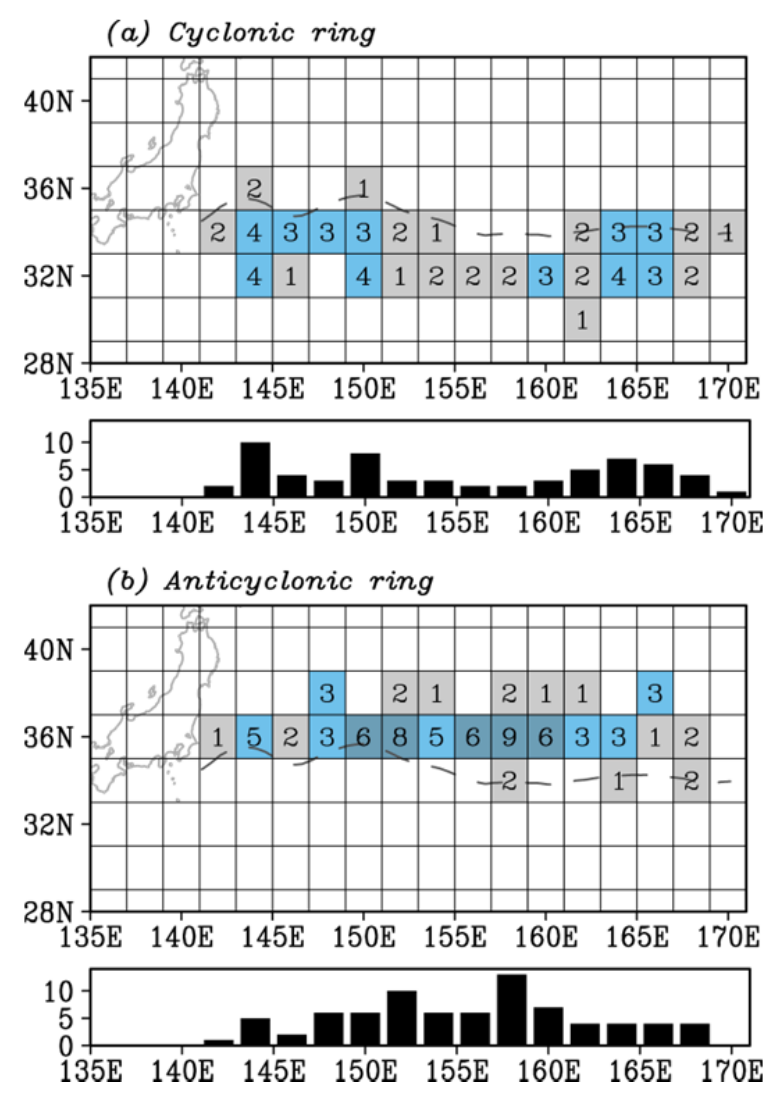

Figure 6. Same as Fig. 5, but the number of (a) cyclonic and (b) anticyclonic ring reabsorption by the KE jet.

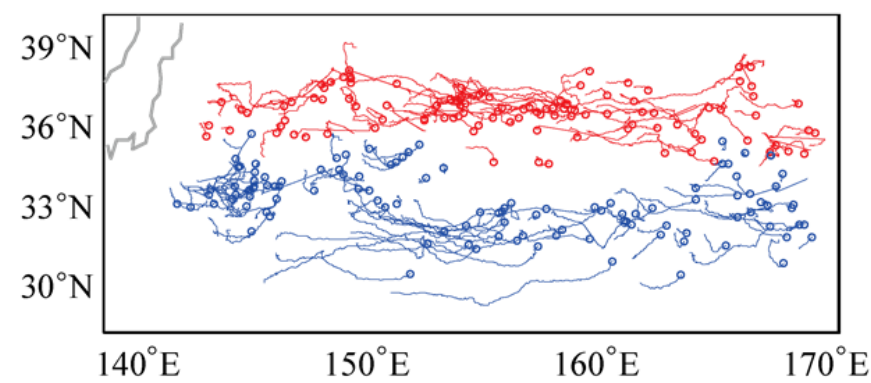

Figure 7. All trajectories of cyclonic (blue) and anticyclonic (red) rings shed from the KE jet. Open circles denote the locations of the ring formations. 


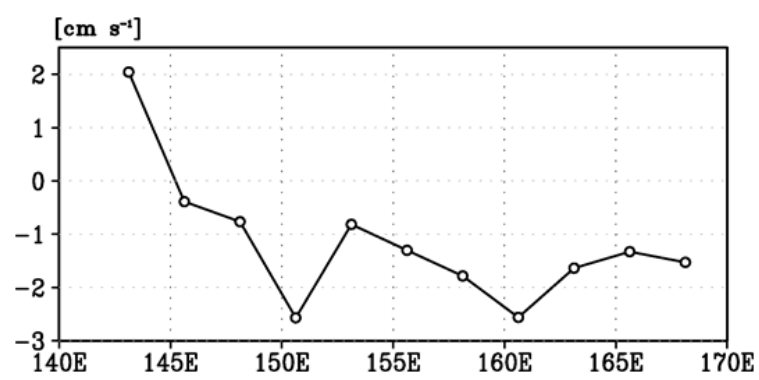

Figure 8. Zonal propagation speed of the KE meander as a function of longitudes. The phase speed is estimated using a lag correlation method (e.g., White et al. 1985).
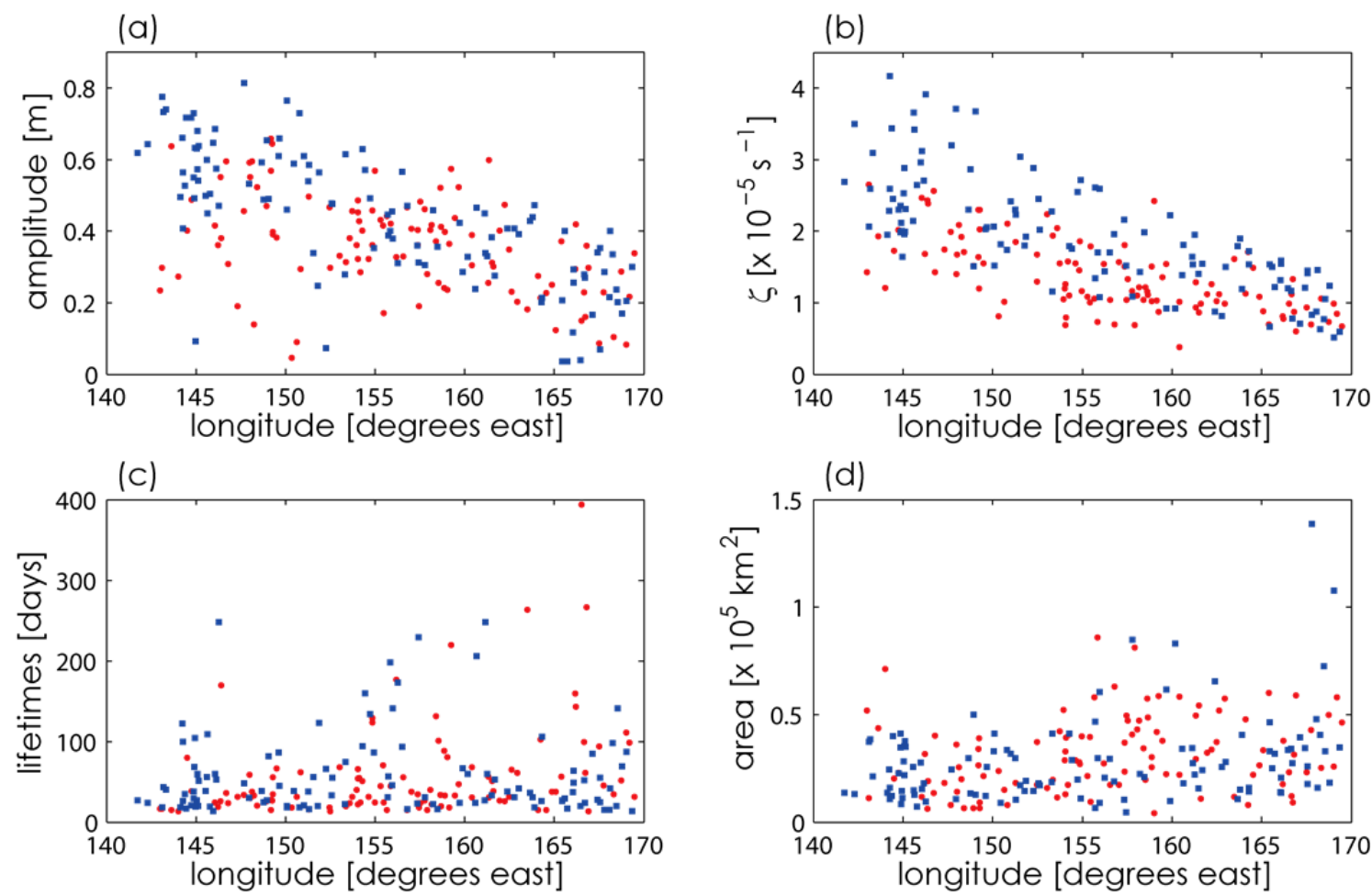

Figure 9. Scatter plots of (a) amplitude, (b) relative vorticity $\zeta$, (c) lifetimes and (d) area of the rings shed from the KE jet as a function of the formation longitude. Red circles and blue squares denote anticyclonic and cyclonic rings, respectively. 
(a) All regions

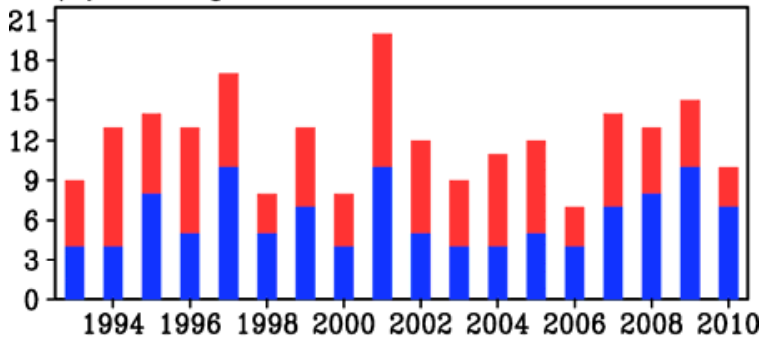

(b) Upstream region

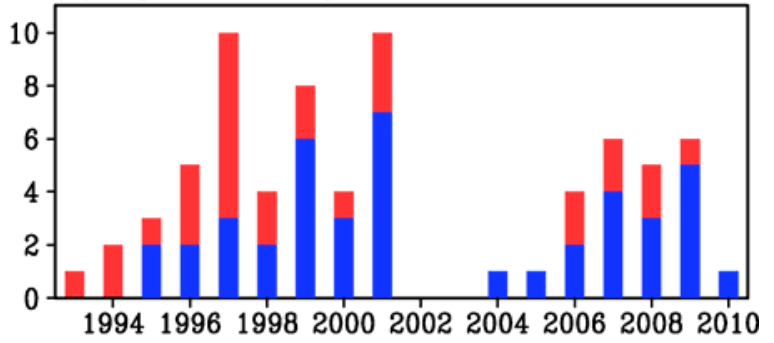

(c) Downstream region

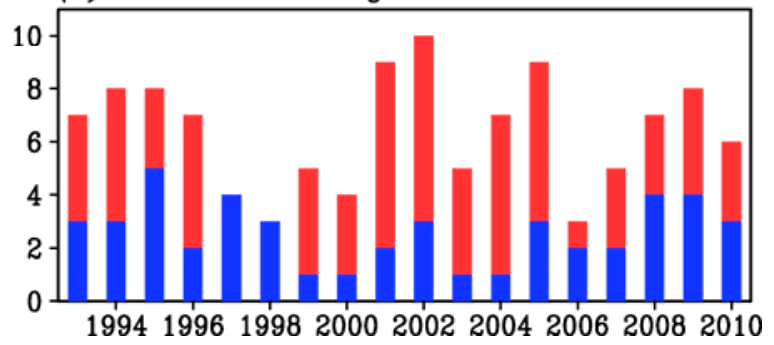

Figure 10. Yearly numbers of the ring formations in (a) all KE region, (b) the upstream KE region from $139^{\circ} \mathrm{E}$ to $151^{\circ} \mathrm{E}$, and (c) the downstream KE region from $153^{\circ} \mathrm{E}$ to $167^{\circ} \mathrm{E}$. The red and blue bars denote anticyclonic and cyclonic rings, respectively.
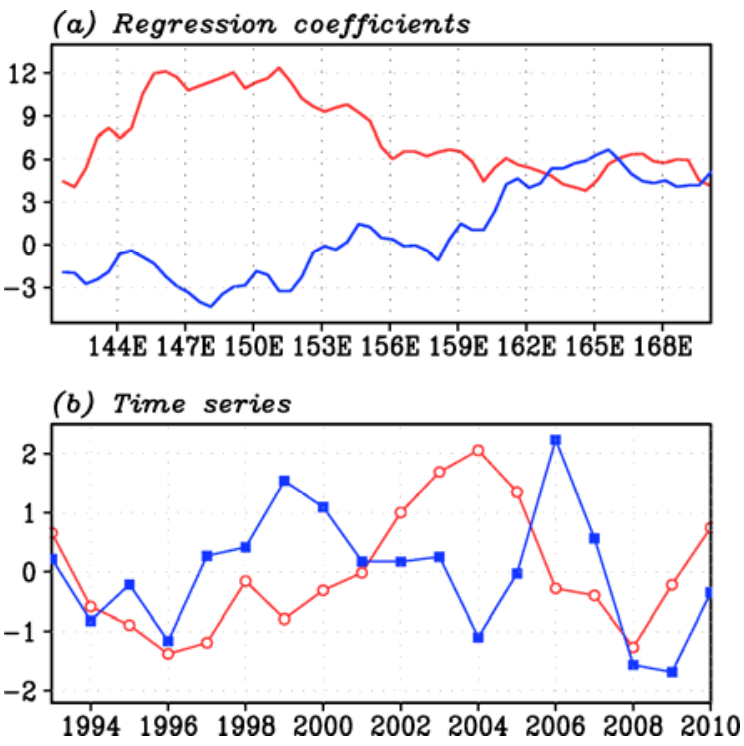

Figure 11. (a) The spatial patterns and (b) time series the first (red) and second (blue) Empirical Orthogonal Function (EOF) modes of the surface geostrophic velocity of the KE jet axis. The explained variances of the first and second EOF modes are $68.5 \%$ and $11.8 \%$, respectively. 

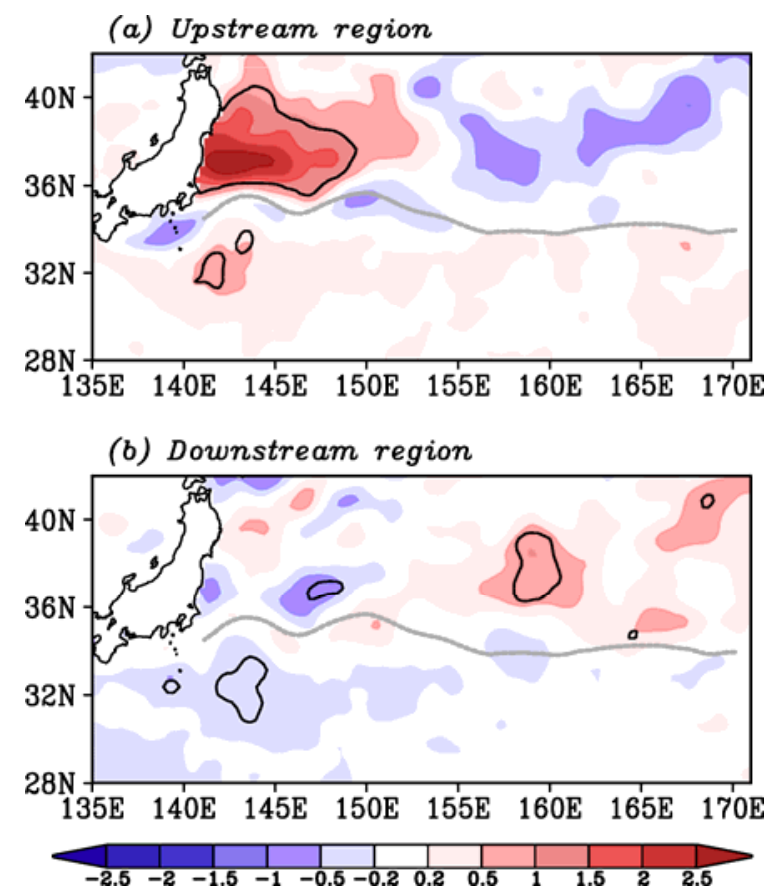

Figure 12. Composite map of SST anomalies between high occurrences minus low occurrences of ring formations in the (upper panel) upstream and (lower panel) downstream regions. Unit is degree. Dashed curve indicates the climatological path of the KE jet. The contour indicates the region where the SST anomalies are statistically significant at 95\% confidence level. 